\title{
Transaction Costs, Information Technology and Development *
}

\author{
Nirvikar Singh \\ University of California, Santa Cruz, USA
}

Revised October 2004

\begin{abstract}
This paper explores potential channels through which information technology (IT) affects economic development. The channel emphasized here is the reduction of transaction costs through the use of information technology. We discuss the nature of transaction costs, their possible impacts on economic outcomes, and the impacts of IT on transaction costs. We provide a theoretical discussion of how a reduction in transaction costs may affect the number of intermediate goods that are produced, and in turn how that number may affect the development path of the economy. We then draw on our fieldwork in rural India that examined the economics of rural Internet kiosks, and relate this multifaceted case study to the theoretical discussion of transaction costs. We conclude with a broader discussion of the potential impact of IT on developing economies.
\end{abstract}

Keywords: transaction costs, information technology, Internet, development, India

JEL codes: O12, O3, L31, P2

Contact: Professor Nirvikar Singh, Department of Economics, E2 Building, University of California, Santa Cruz, CA 95064, USA, ph: 1-831-459-4093, fax: 1-831-459-5077, email: boxjenk@ucsc.edu

\footnotetext{
* This is a revised version of a paper presented at a conference in honor of Pranab Bardhan's contribution to the Journal of Development Economics and to the larger field of development economics, held on September 24-25, 2004 at Harvard University. Pranab Bardhan has been one of my intellectual mentors as well as a co-author, and I hope this paper is a fitting part of the celebration. Some of the research reported in this paper has been supported by grants from the Rajiv Gandhi Institute of Contemporary Studies, International Development Enterprises (India), and the Division of Social Sciences and the Academic Senate of the University of California, Santa Cruz. I am indebted to S. Sivakumar of ITC, P.G. Ponnapa of n-Logue, and Satyan Mishra of Drishtee, for providing me with detailed information on their respective organizations, and for their extensive cooperation. I have received valuable suggestions on this research from Inderjit N. Kaur. Abhijit Banerjee, Dilip Mookherjee, T.N. Srinivasan and Donald Wittman provided useful comments on the previous draft. I alone am responsible for remaining errors and omissions. Finally, I am grateful to the many individuals who generously gave their time at various sites I visited around India.
} 


\section{Introduction}

The problem of economic development, or, rather, its lack, has bedeviled us since colonialism ended, and former colonies became 'developing countries.' There have been some spectacular success stories, but also many failures of development. The result of over fifty years of diverse experiences has been a reasonable degree of agreement among professional economists as to the broad nature of the economic policies that must be followed to promote economic development. One can partly relate this intellectual convergence to the economic success of East Asia and the economic failure of the Soviet Union, both of which became clear only in the last decade or two. Coincidentally, the same period has seen the emergence of information technology (IT) as a major force for change in developed countries. While the virtues of IT have sometimes been overblown, almost to the point of mania, one can assert without too much fear of contradiction that IT has begun to have a significant impact on the lives of people in developed, industrialized countries.

The benefits of IT for developing countries are less clear-cut. IT can improve efficiency, make developing country firms more globally competitive, and bring many benefits to well-off consumers in these countries, whose consumption patterns are close to those of the developed world. From this perspective, IT is a rich-world tool, of limited relevance to the poor masses of developing countries, who lack basic health, sanitation and education. On the other hand, there have been numerous attempts to harness the power of IT in developing countries, to try to improve the delivery of such basic services, as well as provide other services that might have been deemed inaccessible to poor, isolated villagers. Dozens of case studies, newspaper articles and web sites describe various achievements in the use of IT to improve the lives of the poor in poor countries.

What is chiefly missing from the debate on the role of IT in promoting economic development is a unifying conceptual framework for identifying the gains from IT for rural populations in developing countries. This paper provides a beginning in this direction by focusing on transaction costs, how IT affects them, and how they affect development. We argue that IT can significantly reduce the high transaction costs that face poor, rural populations, and that this can have a long-lasting positive impact on economic development. Since we rely on a combination of abstract modeling with informal empirical evidence through case studies, there is no claim that the argument presented here is conclusive - however, we provide a framework for further theoretical and empirical investigation.

The paper is structured as follows. Section 2 provides a general discussion of the concrete role of IT in reducing transaction costs for rural households in developing economies, as well as its more general impacts. Section 3 provides an abstract theoretical discussion, laying out the short-run and long-run impacts of reducing transaction costs on economic development. This section draws on models of 'new growth theory,' and adds transaction costs to these models. Section 4 uses our own fieldwork in India, to examine 
how IT is used in practice, and to get some idea of its qualitative and quantitative impacts. Section 5 briefly concludes, with some more general thoughts on the role of IT in development, including impacts on inequality, expectations, and innovation processes.

\section{Transaction Costs and Information Technology ${ }^{1}$}

While there is no standard definition of the term 'transaction costs', they can be broadly interpreted to include costs associated with market exchange, including costs of searching for options, negotiating contracts and enforcing agreements. ${ }^{2}$ Payments to transaction intermediaries can also be transaction costs, since, in such cases, the intermediary provides costly transaction services, rather than the parties bearing the costs directly. One can also interpret some transportation costs as transaction costs, since they may be required to identify a possible transaction, or to complete it. In this case, as in the case of intermediation, transaction costs are somewhat of a catch-all term for various economically valuable activities that facilitate economic exchanges. We will accept this limitation of the term 'transaction cost,' and highlight varying interpretations where necessary.

Turning to the role of IT, its general economic benefit is that its use may lead to static and dynamic efficiency gains. ${ }^{3}$ Static gains are one-time, and come from more efficient use of scarce resources, allowing higher consumption in the present. More efficient use of resources can include improvements in operating efficiency, as well as reduced transaction costs, though the conceptual boundary between these two avenues may not always be hard and fast. ${ }^{4}$ Dynamic gains come from higher growth, potentially raising the entire future stream of consumption. Simply freeing up current resources through reducing transaction costs can lead to higher growth - in this case, the impacts of lower transaction costs are merely through a conventional channel. On the other hand, as we examine in Section 3, there may be less obvious consequences of transaction costs for growth.

\footnotetext{
${ }^{1}$ This section draws heavily on Singh (2004). See also Singh (2002), and the concluding section of this paper for a broader discussion of the potential role of IT in development. See Kaushik and Singh (2004) for references to the growing literature on the subject.

${ }^{2}$ While Coase (1937) does not use the term, his 'marketing costs' are the essence of the modern concept. Williamson, for example $(1975,1981)$, extends the analysis of transaction costs to relationships within organizations.

${ }^{3}$ Equity is often paired with efficiency in concerns for welfare. Depending how IT is deployed and accessed, the impact on inequality can go either way. However, to the extent that transaction costs are relatively higher for poorer people, the benefits of IT may be greater for the poor, if they can access ITbased tools in an affordable manner. A related issue is that development can also include improvements in the capabilities of the population, such as education, health and nutrition, independently of the direct or indirect economic impact of these improvements. The ability to participate in democratic decision-making can also be placed in this category. IT may also effect improvements along these 'non-economic' dimensions: see Section 5 for further discussion.

${ }^{4}$ Essentially, this is because transaction costs can be interpreted to include internal firm decision-making and implementation costs, as well as market-related transaction costs. Also, the choice of whether marketrelated transaction costs are incurred or not is endogenous to the system, and depends on the relative costs of organizing production in different ways: this is, of course, the basic insight of Coase (1937).
} 
To discuss the efficiency impacts of IT more concretely, note that IT in our usage refers to the electronic processing, storage and communication of information, where anything that can be represented in digital form is included in the term 'information.' Thus news, entertainment, personal communications, educational material, blank and filled-out forms, announcements, schedules, and so on are all information. Software programs that process data (searching, tabulating, and calculating, for example) are also information in this sense, representing a particular kind of intermediate good. We can use standard economic characterizations to classify the different kinds of information. For example, entertainment, personal communications, and sometimes news, are final goods. Educational material, job announcements, or some kinds of news (weather news for farmers, for example) are intermediate goods, typically used for improving incomeearning opportunities. Information about products and services available in the market is also an intermediate good, which can reduce transaction costs for those products.

The ability to share information among users can impact the feasibility of providing it on a commercial basis: information goods typically have the characteristic that one person's use does not reduce their availability for another person. Thus, a message or weather news can be viewed by many people, either simultaneously or sequentially. Depending on the content of the news or message, different people may place different valuations on the information. Only friends and relatives may be interested in a personal message, all farmers in a district may be interested in local weather news, and so on. The use of IT can dramatically increase the shareability of information, and this affects the economics of private and public provision of information goods and services.

For both public and private provision, IT can increase efficiency by economizing on resource use in the operations of firms, as well as in market transactions. Information that would otherwise be conveyed through face-to-face contact, post, courier, print delivery, telegraph or telephone may instead be communicated in digital electronic form via the Internet. The Internet and other digital technologies can also make telephones and printing more efficient, so the role of IT is much more pervasive than simply substitution of the Internet for existing methods. However, a central advantage of the Internet is its potential for enabling detailed two-way information exchange at relatively low cost. ${ }^{5}$ Efficiency benefits of IT are not restricted to just the process of communication. IT can make it possible to track and analyze communications, or, more generally, to store and retrieve information. In fact, word processing, maintaining accounts, inventory management, and many such activities that do not necessarily require long-distance communications or physical movement are also made more efficient by IT.

Experience with Internet use in developed countries suggests that information exchange related to the completion of market transactions is especially valuable. The ability of IT-based communications (combined with storage and processing) to bring

\footnotetext{
${ }^{5}$ Of course, IT also requires new investment, so the benefits of trips, time and paper saved must be weighed against the costs of installing and maintaining the new infrastructure. This is a standard economic calculation.
} 
together buyers and sellers more effectively represents major potential gains. These gains can come about through lower search costs, and the resulting improvement in matching of buyers and sellers. The successes of auction and employment websites in the US illustrate these gains. In a developing country, farmers selling their crops and buying inputs, parents seeking matrimonial alliances for their children, and job seekers could all be potential users of Internet-based matching services.

Efficiency gains of IT can also come about through the enabling of new goods and services. In many cases, the new good is related to something available earlier, but is presented in a form that reduces costs and expands the size of the market. For example, recorded music is a mass-consumption item, whereas only a small minority of the population could afford or have access to live performances by the highest quality musicians. In this case, while digital recording reduced production costs, digital delivery has reduced transaction costs, and further expanded the market. Educational material is another example where recording and duplication can replace more expensive, skilledlabor-intensive alternatives for delivery. The possibilities for interactivity with IT-based educational materials illustrate the advantages of IT over older technologies based only on recording and duplication. Long-distance interactive communication in educational contexts can also be considered as a reduction in transaction costs, since physical travel is eliminated or reduced.

IT may also play an important role in reducing the transaction costs associated with the provision of public goods and with redistributive transfer payments. Citizens, especially in developing countries, typically incur private costs (often substantial) in availing of government-provided services. ${ }^{6}$ Reducing these costs requires the internal use of IT by government, as well as enabling the beneficiaries of government services (particularly the economically disadvantaged) to access IT resources also. While governments may invest in such front-end interfaces with citizens (and have done so in developed countries), the cost of doing so for governments in developing countries may be prohibitive. Such governments typically already have difficulties in raising sufficient resources through taxes and user charges for traditional public sector activities. However, successful examples of implementation of 'e-governance' initiatives do exist. ${ }^{7}$ There is also a conceptual alternative that economizes on government resources. The use of IT can increase the scope for private provision of intermediary services that reduce the cost of access to government. Private intermediaries already help in filling out forms, getting access, and so on, but IT can reduce costs further, often by an order of magnitude. In broad terms (as is also the case with electronic marketplaces and job-matching boards), IT changes the scope and nature of intermediation.

In developing countries, 'cyber kiosks' have already proliferated in cities and larger towns, with usage patterns often quite similar to those in developed countries. Urban population densities, income levels, cultural attitudes and telecom infrastructure all

\footnotetext{
${ }^{6}$ These transaction costs include government officials illegally demanding ‘speed money’ or other payments.

${ }^{7}$ In India, these include Bhoomi in Karnataka, e-seva in Andhra Pradesh, Lokmitra in Rajasthan, and the CHOICE Project in Chattisgarh. See also Bhatnagar and Schware (2000) for further examples.
} 
seem to be sufficient for the commercial success of these enterprises. The falling cost of hardware and a variety of software have also supported this trend. However, one can argue that sustained and broad-based economic development requires improved productivity and more efficient resource use in rural areas. On the other hand, in rural areas the various demographic and socioeconomic variables may not be present in configurations that would easily enable the diffusion of commercial access to various ITenabled services. Other barriers include the market power of traditional rural intermediaries and local language requirements and different demand patterns for software. Nevertheless, a case can be made that transaction costs are relatively ${ }^{8}$ very high in rural areas of developing countries, and that IT can bring those costs down. The issue may be one of cost-effective provision of IT access, rather than the absence of IT-based efficiency gains.

We therefore briefly discuss, in somewhat more specific terms, the potential impacts of rural IT use in developing countries. Possible sources of demand for IT-based services can be framed in terms of a flow diagram representing the decisions of rural households. We will treat a typical household as engaged in farming, though this will not be true for all of them. Figure 1 presents a simplified representation of the various economic decisions

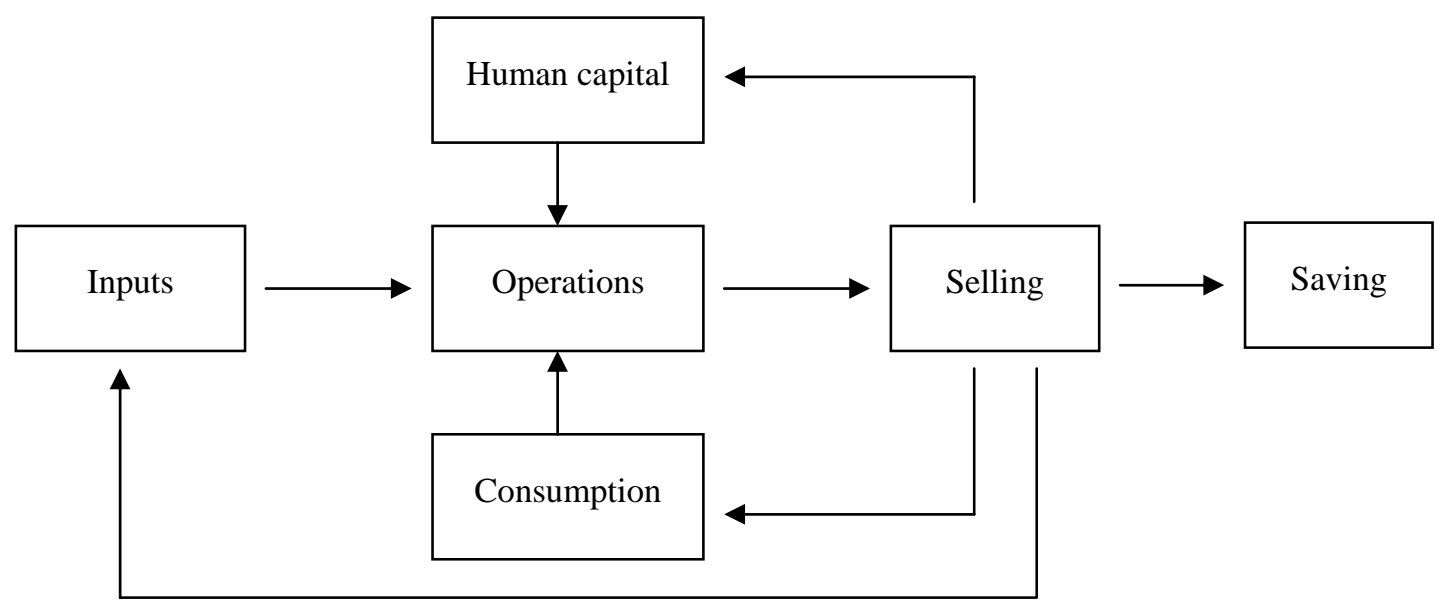

Figure 1

Beginning from the left of Figure 1, input decisions include material inputs such as seeds, fertilizer and pesticides; and capital inputs such as tractors and land (whether through purchases or rentals); as well as the credit required for such purposes. The focus of analysis will be market transactions for inputs, in keeping with the emphasis on transaction costs. In all cases, there is a potential for benefiting through better

\footnotetext{
${ }^{8}$ While urban residents may also face significant transaction costs in making purchases, or accessing government services, they may be lower in absolute terms than for rural populations, because the latter face higher transportation costs, and they may also be lower relative to incomes.
} 
information about prices, quality and availability. Labor is also an important input, but the labor market has special characteristics (lack of mobility, contracting, relationship factors, etc.) that reduce the importance of such information in rural contexts.

Operations include decisions with respect to quantity and timing of inputs. A crucial aspect of agricultural operations is risk management, as both the weather and pest incidence are extremely variable. Both ex ante decisions in the face of uncertainty and ex post responses to realizations of uncertainty are important. In this context, predictive and technical information both matter for agricultural operations. Continuing to the right of Figure 1, marketing of outputs primarily requires price information. Increasingly, producing for sale also requires knowledge of quality requirements in different markets. ${ }^{9}$ Selling of produce provides income for consumption, investment and inputs (the reverse arrows in the figure), as well as generating information that affects input and production decisions.

Non-production decisions of households can be roughly divided into pure consumption activities and human capital investment, in education and health. The boundary is fuzzy, since even basic food consumption has nutritional impacts and therefore a human capital component. These activities generate impacts on operations, since they affect the quality of decision-making, as well as household labor inputs: we indicate this with the vertical arrows. While poorer households may be severely limited in their consumption, a significant proportion of rural households in countries such as India have incomes sufficient to support some discretionary consumption. In some cases, consumption may be only superficially discretionary - social norms may dictate spending on activities relating to marriage and other life cycle events. Finally, the rightmost box captures household saving, again something that is not feasible for all rural households, but is an activity of growing importance. Saving may be for consumption smoothing, investment, or precautionary reasons.

Even this simplified and summary picture of rural households' economic activity illustrates that they engage in a broad range of transactions and decisions with economic impacts. What is noteworthy besides this complexity is that many decisions are made with very limited information, and that market interactions are often subject to high transaction costs, due to imperfections in information, high transportation costs, inefficient intermediation and time delays. High transaction costs will always prevent marginal transactions from being undertaken; in extreme cases, the market may fail to function at all. Given this situation, the potential role of IT can be understood in terms of reducing transaction costs, as well as improving the efficiency of decision making within households (both as producers and as consumers).

Reductions in communication and transaction costs are particularly beneficial where they can allow new markets to develop, in the sense that existing goods and services, otherwise restricted to urban areas, or to a very limited segment of rural populations, now can be offered to broad cross-sections of the rural population. Examples

\footnotetext{
${ }^{9}$ This reflects increased processing of food products, as well as greater exports to markets where regulatory standards for quality and consumer consciousness are significant.
} 
include financial services, particular types of education, health services, long distance communications, and expertise on a range of production-related decisions. Whether this can be done in a sustainable manner depends on the supply conditions for IT-based rural services.

It must be further understood that the activities outlined, in Figure 1 and the accompanying discussion, take place within a particular institutional environment. This includes private actors as well as governments. For example, farmers may obtain credit and inputs from, as well contract their output to, private 'commission agents,' even in the presence of government procurement and government-run local markets. Governments play a major role in subsidizing inputs, providing infrastructure, and enforcing property rights. To the extent that these activities are also subject to inefficiencies, it may be the case that, in order to be successful, IT-based interventions geared towards rural households will have to simultaneously alter the institutional environment, or else achieve sufficient scale and scope in order to impel changes in it. We will take this up later in the paper.

\section{Modeling Transaction Costs and Development}

The simplest and most basic aspect of transaction costs is that they result in resources used up in exchange, and drive a wedge between the supply price and the demand price. For example, in a linear model of competitive supply and demand (e.g., Bussolo and Whalley, 2002), we have

$$
\begin{aligned}
& P_{d}=a-b Q_{d} \\
& P_{s}=c+Q_{s} \\
& Q_{d}=Q_{s} \\
& P_{d}=P_{s}+t
\end{aligned}
$$

In equation (4), $t$ is the unit transaction cost, which has a negative impact on equilibrium quantity, as seen in the following expression.

$Q_{e}=\frac{a-c-t}{b+d}$

If transaction costs are high enough, the market does not exist, in the sense that the quantity exchanged is zero. If the transaction cost is purely resources used up in the process of exchange, then the welfare loss from its existence consists of the usual Harberger deadweight loss triangle, as well as the rectangle $t Q_{e}$, which can be substantially larger. If the transaction cost is actually a payment to an intermediary, or a tax imposed by the government, then the welfare loss is just the Harberger triangle. One can argue that, if transaction costs are high, perhaps even high enough to lead to a zero equilibrium quantity, then even the Harberger triangle can be quite a substantial welfare loss, and this may be a useful point to make for developing countries such as India. 
Using the above model and variants, Bussolo and Whalley (2002) arrive at estimates of the welfare losses of transaction costs in general equilibrium in an open economy. ${ }^{10}$ Their simulations consider $50 \%$ reductions in exogenous transaction costs in goods markets for all goods and all agents. Using data for the Indian economy, real household income in these simulations rises about $6 \%$ to $13 \%$, depending on the specifics of the model. Bussolo (2001) performs a similar exercise with data for Colombia, and obtains real household income increases that range from about $2 \%$ to $13 \%$ for the various models. The gains here include the transaction cost rectangles, as well as the Harberger triangles.

These exercises provide a useful indication of the static efficiency gains from reducing transaction costs, but that is all. They tell us nothing about the long run impacts on growth or development. Romer (1994), in an influential paper, argues that even if the rectangles represent a redistribution, and not a resource cost, there is a welfare cost that goes well beyond the usual Harberger triangles. The basic idea is that if there is a fixed cost of producing a good, transaction costs can reduce operating profits to the extent that some goods are no longer produced, leading to a larger loss of welfare than would otherwise be the case. Note that the transaction costs can be smaller than would be required to lead to zero quantity in the simple competitive case above.

The essentials of Romer's model and demonstration of welfare losses are as follows. Output is assumed to be a function of labor, L, and a large number of different types of capital goods, indexed by $i$.

$Y=L^{1-\alpha} \sum_{i=1}^{N} x_{i}^{\alpha}$

This is a simple special case of a more general CES aggregation of the differentiated capital goods, where the CES parameter is assumed equal to $\alpha$ (Romer, 1994, p. 27). Each of the capital goods has a fixed cost of production given by $c_{0}$, and it is further assumed that the goods are arranged so that $c_{0}$ is increasing in $i$, and that the dependence is linear, or $c_{0}(i)=\mu i$.

Romer focuses on tariffs as the transaction costs in this model, so all capital goods are assumed to be potentially produced by foreign entrepreneurs. The cost $c_{0}$ in this case can be assumed to be an entry cost for the local market - the model is static at this stage. Good $N$ is the marginal good in the absence of transaction costs. There is a single producer of each type of capital good. ${ }^{11}$ Since the capital goods enter the production

\footnotetext{
10 The CGE models used in this case have theoretical antecedents in treatments of general competitive equilibrium with transaction costs such as Foley (1970) and Hahn (1971). These models take the number of goods as given, and focus on existence of equilibrium rather than welfare issues.

${ }^{11}$ As pointed out to me by Abhijit Banerjee and Dilip Mookherjee, this is a significant assumption, since adjustment takes place at the level of varieties rather than the number of firms producing a particular variety. If there are several potential firms producing each variety, or if individual firms produce several varieties, the nature of competition and pricing becomes more complex, but it seems that fixed costs of
} 
function (6) symmetrically, each of them faces the same inverse demand, given by the value of the marginal product of the input. Using the output as the numeraire, this is simply the marginal product, so that the inverse demand for good $i$ is

$$
p_{i}\left(x_{i}\right)=\alpha L^{1-\alpha} x_{i}^{\alpha-1}
$$

There is an ad valorem tariff, $t$, on all of the purchases of the foreign capital goods, so that if the firm selling good $i$ chooses to enter, its profit maximization problem is

$\max _{x}(1-t) p_{i}(x) x-c_{1} x$

Here $c_{1}$ is the constant marginal cost of production. The result of this maximization is a proportional markup on marginal cost

$$
p_{i}^{*}(t)=c_{1} / \alpha(1-t)
$$

Substituting this in (7), we solve for equilibrium output, assuming that the producer is profitable.

$$
x^{*}(t)=\alpha^{2 /(1-\alpha)} C_{1}^{-1 /(1-\alpha)}(1-t)^{1 /(1-\alpha)} L
$$

Also, substituting (9) in (8), we have that equilibrium profit, before fixed costs of entry are deducted, is

$$
c_{1} x^{*}(t)(1-\alpha) / \alpha
$$

Equating this to $c_{0}(i)=\mu i$ and solving, we derive the expression for the marginal good in equilibrium:

$$
N(t)=c_{1} x^{*}(t)(1-\alpha) / \alpha \mu
$$

Domestic income is obtained by substituting (10) and (12) in (6), and national income is given by

$Y_{N A T}(t)=(1-\alpha) Y_{D O M}(t)+t \alpha Y_{D O M}(t)$

The first term on the right hand side of (13) is labor's share of domestic product, while the second term is tariff revenue. Romer goes on to demonstrate the difference in welfare cost when the number of capital goods in assumed to be fixed at $N(0)$, versus the case where it is determined in equilibrium as a function of the tariff rate, $t$. In particular, he shows that, when $\alpha=0.5$, 
$1-\left.\frac{Y_{N A T}(t)}{Y_{N A T}(0)}\right|_{N=N(0)}=t^{2}$

whereas

$1-\frac{Y_{N A T}(t)}{Y_{N A T}(0)}=2 t-2 t^{3}+t^{4}$

In the first case, a tariff rate of $10 \%$ implies a drop in national income of $1 \%$, but in the second case, where the impact of the tariff on the equilibrium number of capital goods used is accounted for, the decrease is $19.8 \%$.

Romer's important insight has led to several papers that try to quantify the impacts of trade liberalization on the economy, in terms of leading to new goods being traded. While these empirical studies do not necessarily correspond precisely to Romer's theoretical model, they point out impacts of trade liberalization that are similar in spirit. Kehoe and Ruhl (2003) find substantial increases in the number of goods traded, for bilateral trade flows for the countries in NAFTA and in the European Union. Panagariya (2004) reports similar results for India, based on work by one of his doctoral students. Funke and Ruhwedel (2003) find substantial increases in product variety in international trade for 14 central and eastern European countries after the fall of the Soviet Union. ${ }^{12}$

The empirical studies above have all focused on tariffs as a cause of suboptimal product variety and resultant welfare losses. As Romer (1994) notes in his general discussion, but does not emphasize in his modeling, his insight applies to any form of transaction costs, not just tariffs. ${ }^{13}$ Thus, communication and search costs for domestic goods, which are most directly affected by information technology, can have the same effects. Therefore, suppose that the parameter, $t$, represents a resource cost for transactions that is proportional to revenue, but that the suppliers of the capital goods are domestic firms. Then we have

$$
Y_{N A T}(t)=(1-\alpha) Y_{D O M}(t)+(1-t) \alpha Y_{D O M}(t)
$$

The first term is the same as in equation (13), but the second term is the total payment received by the domestic capital goods producers. ${ }^{14}$ In this case, again with $\alpha=0.5$, the

\footnotetext{
${ }^{12}$ Hummels and Klenow (2002) also examine product variety in trade, but in the context of the impacts of countries' size and other characteristics.

${ }^{13}$ In the context of international trade, iceberg trade costs (which include transportation costs), as applied by, e.g., Obstfeld and Rogoff (2000) are modeled similarly.

${ }^{14}$ Here we assume that the resources used up by transaction costs are simply a waste, and do not show up in the national income accounting. On the other hand, fixed and variable costs of capital goods producers are payments to domestic labor, and so are included in national income. I am grateful to T.N. Srinivasan for clarifying this assumption. One can alter the specific assumptions of what is pure waste and what is paid to others, without altering the thrust of the calculations that follow.
} 
welfare loss when the reduction in the number of goods is accounted for is higher, but only by a multiple, and not an order of magnitude. Specifically, we have,

$1-\left.\frac{Y_{N A T}(t)}{Y_{N A T}(0)}\right|_{N=N(0)}=1.5 t-0.5 t^{2}$

and

$1-\frac{Y_{N A T}(t)}{Y_{N A T}(0)}=4 t-6 t^{2}+4 t^{3}-t^{4}$

Thus, transaction costs that are $5 \%$ of revenue result in income losses of approximately $7.5 \%$ and $20 \%$, respectively.

Another possibility is that transaction costs are proportional to profit rather than revenue. In this case, the calculations must be modified more thoroughly. In particular, the equilibrium price becomes $p_{i}{ }^{*}=c_{1} / \alpha$, independent of $t$, and the expression for equilibrium use of the capital goods is also modified, and is independent of the transaction cost. However, profit still depends on $t$, and so does the number of capital goods produced and used. In this case, the Romer result on order of magnitude differences again does not hold, but, as in the previous case, there is a multiplier difference. In particular, for any $\alpha$,

$1-\left.\frac{Y_{N A T}(t)}{Y_{N A T}(0)}\right|_{N=N(0)}=t$

while

$1-\frac{Y_{N A T}(t)}{Y_{N A T}(0)}=2 t-t^{2}$

One should not read too much into the comparisons. In particular, they should not be used to infer that tariffs are worse than domestic transaction costs. The point is really to emphasize the generality of Romer's insight. If one is interested in development, the main implication of domestic transaction costs, i.e., their effect on the equilibrium number of intermediate goods, and hence on output and welfare, must be sought in a dynamic model. Romer hints at this link, since he informally relates his discussion to the branch of "new" growth theory that emphasizes growth through endogenous innovation (Romer, 1994, p. 6). Here we make this connection somewhat more precise, using the analysis of Ciccone and Matsuyama (1996).

Ciccone and Matsuyama (1996) use a dynamic monopolistic competition model, in which an economy that inherits a small range of differentiated intermediate inputs can 
be trapped into a lower stage of development. ${ }^{15}$ In particular, their model may have multiple steady state equilibria, and the starting point of the economy can determine which steady state is approached. How the intuition of the Romer model will be used is straightforward. If transaction costs determine the initial conditions in terms of the number of varieties of the intermediate good, then reducing transaction costs may jump start the economy, moving it to a path that leads to a higher steady state. In addition, transaction costs will affect the long-run equilibrium number of varieties, and hence the level of the steady state. We sketch a version of the Ciccone-Matsuyama model with the addition of transaction costs, and indicate how the impact of reduced transaction costs plays out in the context of the model.

The model is set in continuous time. In this economy households that supply labor inelastically, and have a logarithmic instantaneous utility function for the single consumption good. Intertemporal utility maximization gives the standard Euler condition, where $C_{t}$ is consumption, $\rho$ is the subjective discount rate, and $R_{t}$ is the cumulative interest factor up to time $t$.

$$
\frac{\dot{C}_{t}}{C_{t}}=\dot{R}_{t}-\rho
$$

The consumption good is produced by identical competitive firms, with CRS production technology described by $C_{t}=F\left(X_{t}, H_{t}\right)$, where $H_{t}$ is labor input (with competitive wage rate of $w_{t}$ ) and $X_{t}$ is the composite of the differentiated intermediate inputs, which, in this dynamic model, must be interpreted as perishable producer services rather than capital goods. However, this is basically the same specification as Romer (1994) and similar growth models. Here, a continuum of inputs is assumed, and, unlike in Romer's example, the CES elasticity is not pinned down to any parameter of the production function, though it is assumed that $\sigma>1$. We have

$$
X_{t}=\left[\int_{0}^{n_{t}}\left(x_{t}(i)\right)^{1-1 / \sigma} d i\right]^{\sigma /(\sigma-1)}
$$

Growth in this economy comes about through an increase in the number of varieties of intermediate inputs, $n_{t}$. In fact, factor productivity increases with the range of differentiated inputs. By symmetry, $x(i)=x$, so, from (22), the productivity of intermediate inputs is $X / n x=n^{1 /(\sigma-1)}$, which is increasing in $n$ as long as $\sigma>1$. One way to introduce transaction costs into this framework is to assume that some fraction, say $\tau_{1}$, of the composite input $X_{t}$ is consumed by such costs. In this case, the production function

\footnotetext{
${ }^{15}$ As Ciccone and Matsuyama point out, their basic model is very similar to that of Grossman and Helpman (1991, Ch. 3.1) - the crucial difference being that substitution between labor and differentiated capital goods is allowed. This assumption drives the equilibrium possibilities discussed later in this paper.
} 
becomes $C_{t}=F\left(\left(1-\tau_{1}\right) X_{t}, H_{t}\right) \cdot{ }^{16}$ However, we will pursue a more fruitful alternative below.

As in Romer (1994), and other such models, the supply of intermediate goods is characterized by monopolistic competition: each differentiated input is produced by a single firm, which faces a demand curve with constant price elasticity, $\sigma$. Each input uses only labor in production, with constant returns. Following Ciccone and Matsuyama, the unit labor requirement is $a_{X}$, but the units of measurement are chosen to make this equal to $(1-1 / \sigma)$. Profit maximization implies marginal revenue equals marginal cost, or, in the absence of transaction costs,

$$
p_{t}(i)\left(1-\frac{1}{\sigma}\right)=a_{X} w_{t}
$$

Using the normalization for $a_{X}$, we have, simply, $p_{t}(i)=w_{t}$. If we introduce transaction costs at this stage of production, as in the static Romer (1994) model discussed earlier, the equilibrium price becomes, instead,

$$
p_{t}(i)=w_{t} /\left(1-\tau_{2}\right)
$$

Using (24), the price index for the composite intermediate good is

$$
P_{t}=\left[\int_{0}^{n_{t}}\left(p_{t}(i)\right)^{1-\sigma} d i\right]^{1 /(1-\sigma)}=n_{t}^{1 /(1-\sigma)} w_{t} /\left(1-\tau_{2}\right)
$$

Note that $P_{t}$ is decreasing in $n_{t}$, the number of varieties.

Since the final goods sector is perfectly competitive, the gross share, say $\alpha$, of the composite intermediate good in the final output is given by the expression $F_{X} X / F$, but only a fraction, $\left(1-\tau_{2}\right)$, is received by the intermediate goods firms, while the remaining fraction is lost through transaction costs. With transaction costs in the use of the composite input, $F_{X}=\left(1-\tau_{1}\right) F_{1}$, so transaction costs also reduce the input's share by reducing its marginal productivity. Also, since $F$ is a CRS function, the input share depends only on the relative input price, so $\alpha=\alpha(P / w)$. For simplicity, we shall focus only on the second source of transaction costs, and set $\tau_{1}$ equal to zero for the rest of the analysis. Using (25), we have,

$$
\alpha_{t}=\alpha\left(n_{t}^{1 /(1-\sigma)} /\left(1-\tau_{2}\right)\right) \equiv A\left(n_{t}, \tau_{2}\right)
$$

\footnotetext{
${ }^{16}$ It is important to reiterate that the transaction cost parameters in these abstract models can have varying interpretations, and can stand for a wide range of technologically- or policy-induced costs: this is to be expected at this level of abstraction.
} 
The function $A$ is increasing in $n_{t}$, as long as the elasticity of substitution between $X$ and $H$, say $\theta$, is greater than one: Ciccone and Matsuyama provide references that argue for the empirical plausibility of this assumption. The function $A$ now also depends on $\tau_{2}$, and will be decreasing in the second argument as long as $\theta>1$. Intuitively, as intermediate goods producers increase prices to compensate for transaction costs, higher substitutability of labor for their inputs reduces their share. Their net share, $\left(1-\tau_{2}\right) \alpha$, is even lower, and is also decreasing in $\tau_{2}$.

For any variety, using symmetry, we can drop the index $i$, and write net profit as

$$
\pi_{t}=\left(p_{t}\left(1-\tau_{2}\right)-a_{X} w_{t}\right) x_{t}=p_{t}\left(1-\tau_{2}\right) x_{t} / \sigma
$$

Now, net revenue for all varieties of the intermediate goods is $n_{t} p_{t}\left(1-\tau_{2}\right) x_{t}=\left(1-\tau_{2}\right) \alpha_{t} F_{t}$, where the right hand side is the net input share. However, consumption is now less than output, as a result of the transaction costs measured by $\tau_{2}$. The share of output lost through these transaction costs is $\alpha_{t} \tau_{2}$. Hence, the share of intermediate goods firms in consumption is $\alpha_{t}\left(1-\tau_{2}\right) /\left(1-\alpha_{t} \tau_{2}\right)$. Hence, we get, using (26), ${ }^{17}$

$\pi_{t}=A\left(n_{t}, \tau_{2}\right)\left(1-\tau_{2}\right) C_{t} /\left(1-A\left(n_{t}, \tau_{2}\right) \tau_{2}\right) n_{t} \sigma$

Following Ciccone and Matsuyama, assume that the number of firms starts at $n_{0}$, that there is free entry subject to a start-up cost of $a_{n}$ units of labor per intermediate variety, and that these costs are financed through issuing ownership shares. ${ }^{18}$ Let $v_{t}$ be the value of any intermediate goods firm. Then, in equilibrium, we have:

$$
w_{t} a_{n} \geq v_{t}, \quad \dot{n}_{t} \geq 0, \quad\left(w_{t} a_{n}-v_{t}\right) \dot{n}_{t}=0
$$

Since the market value of an intermediate goods firm is equal to the present value of its profits, we get

$$
\left(\pi_{t}+\dot{v}_{t}\right) / v_{t}=\dot{R}_{t}
$$

Letting $V=v / C$, and using (21), 28) and (30), we get

$$
\dot{V}_{t}=\rho V_{t}-A\left(n_{t}, \tau_{2}\right)\left(1-\tau_{2}\right) /\left(1-A\left(n_{t}, \tau_{2}\right) \tau_{2}\right) n_{t} \sigma
$$

\footnotetext{
${ }^{17}$ This equation reduces to equation (7) in Ciccone and Matsuyama (1996) when transaction costs are zero.

${ }^{18}$ These start-up costs can also involve transaction costs. Romer quotes de Soto (1989), in reference to a test case conducted in Peru in 1983, where it took four university students 289 days of full time work to get the 11 permits needed to legally open a small garment assembly shop. Such transaction costs may also be reduced by the use of IT, though clearly policy changes are also required.
} 
When $\dot{V}_{t}=0$ (31) yields the equivalent of Ciccone and Matsuyama's (VV) curve (expressing $V$ as a function of $n$ ) in a phase diagram of the economy's dynamics. ${ }^{19}$ In our case, the curve depends also on $\tau_{2}$, and shifts in $V$ - $n$ space as $\tau_{2}$ changes. The nature of this shift depends on how the term $A\left(n_{t}, \tau_{2}\right)\left(1-\tau_{2}\right) /\left(1-A\left(n_{t}, \tau_{2}\right) \tau_{2}\right)$ responds to changes in $\tau_{2}$. A necessary and sufficient condition for this expression to be decreasing in $\tau_{2}$ is that $A\left(n_{t}, \tau_{2}\right) \tau_{2}$ is increasing in $\tau_{2}$. We shall assume that this property holds, so that the (VV) curve shifts downward as $\tau_{2}$ increases. We discuss the implications of this property later in this analysis. Note that as long as $A\left(n_{t}, \tau_{2}\right)$ is increasing in $n$, then so is the term $A\left(n_{t}, \tau_{2}\right)\left(1-\tau_{2}\right) /\left(1-A\left(n_{t}, \tau_{2}\right) \tau_{2}\right)$ : hence the qualitative properties of the VV-locus are unaffected by the presence of transaction costs. is given by

Next, assuming that the total supply of labor is $L$, equilibrium in the labor market

$$
L=a_{n} \dot{n}_{t}+H_{t}+n_{t} a_{X} X_{t}
$$

We substitute the following equalities, for payments to intermediate goods and labor in the production of the final good, into (32):

$$
\begin{aligned}
& n_{t} p_{t}\left(1-\tau_{2}\right) x_{t}=n_{t} w_{t} x_{t}=\alpha_{t}\left(1-\tau_{2}\right) C_{t} /\left(1-\alpha_{t} \tau_{2}\right) \\
& w_{t} H_{t}=\left(1-\alpha_{t}\right) C_{t} /\left(1-\tau_{2}-\alpha_{t} \tau_{2}\right)
\end{aligned}
$$

Hence, we have

$$
L=a_{n} \dot{n}_{t}+\left(1-\alpha_{t}\right) C_{t} /\left(1-\alpha_{t} \tau_{2}\right) w_{t}+(1-1 / \sigma) \alpha_{t}\left(1-\tau_{2}\right) C_{t} /\left(1-\alpha_{t} \tau_{2}\right) w_{t}
$$

This simplifies to

$$
L=a_{n} \dot{n}_{t}+\left(1-\frac{A\left(n_{t}, \tau_{2}\right)\left(1-\tau_{2}\right)}{\left(1-A\left(n_{t}, \tau_{2}\right) \tau_{2}\right) \sigma}\right)\left(\frac{C_{t}}{w_{t}}\right)
$$

This equation generalizes (10) in Ciccone and Matsuyama, and, rearranging and using (29), we have the analogue of their equation (13b):

$$
\dot{n}_{t}=\max \left\{\frac{L}{a_{n}}-\left(1-\frac{A\left(n_{t}, \tau_{2}\right)\left(1-\tau_{2}\right)}{\left(1-A\left(n_{t}, \tau_{2}\right) \tau_{2}\right) \sigma}\right) \frac{1}{V_{t}}, 0\right\}
$$

Setting the first term in the outside brackets equal to zero, and expressing $V$ as a function of $n$ (and $\tau$ ), one obtains the generalization of Ciccone and Matsuyama's (NN) curve in $V$ - $n$ space . Differentiation with respect to $\tau_{2}$ shows that the (NN) curve shifts upward as

${ }^{19}$ Equation (31) reduces to (13a) in Ciccone and Matsuyama when transaction costs are zero. 
transaction costs increase, given our assumption that $A\left(n_{t}, \tau_{2}\right) \tau_{2}$ is increasing in $\tau_{2}$. Note that here the impact of an increase in transaction costs is similar to that of an increase in start-up costs, but the latter has no impact on the (VV) curve.

We can now begin to discuss the dynamic implications of transaction costs in this model, i.e., the implications for development. First, consider the case, where $\theta \leq \sigma$. Ciccone and Matsuyama show that there is a unique intersection of the (VV) and (NN) curves, which is the lowest steady state equilibrium. This is shown in Figure 2, where the intersection occurs at $n^{*}$. If the economy begins to the left of $n^{*}$, it converges to $n^{*}$. To the right of $n^{*}$, the number of intermediate goods firms does not change, and the economy stays on the corresponding point on (VV). Here, initial conditions do not matter 'too much', since any economy starting to the left of $n^{*}$ will end up at the same steady state. Thus, the impact of transaction costs on initial conditions, as emerges from the Romer (1994) model, is muted in the long run. However, transaction costs affect the steady state itself, as one would expect. An increase in $\tau_{2}$ shifts (VV) downward and (NN) upward, thereby reducing $n^{*}$, and hence the long run level of development.

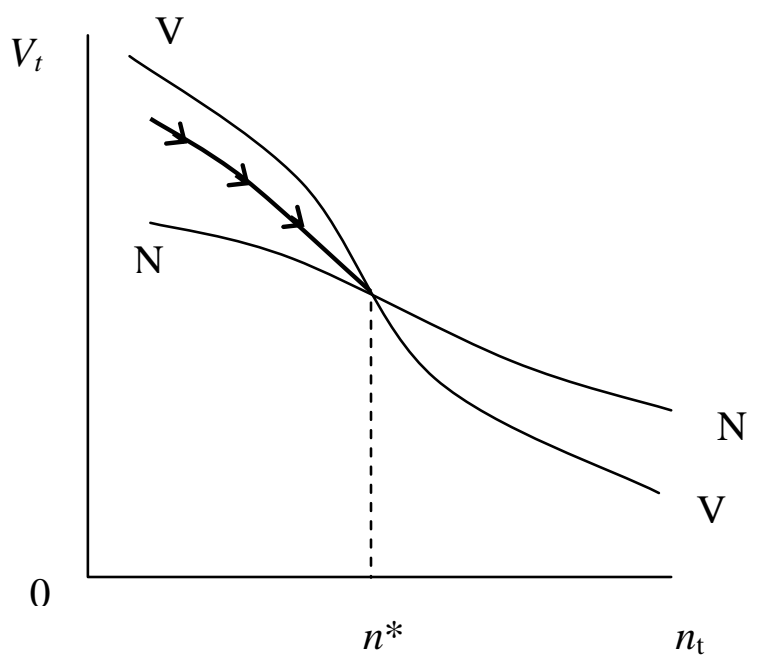

Figure 2

Alternatively, if $F$ has a CES form with $\theta>\sigma$, Ciccone and Matsuyama illustrate three possibilities, as shown in Figure 3a-c. ${ }^{20}$ Now (VV) is no longer downward sloping everywhere, but has the possible humped shape as illustrated. In Figure 3a, (NN) lies completely above (VV), and any point on (VV) is a steady state - no development takes place. In Figure 3b, (NN) intersects (VV) twice, both where (VV) is downward sloping. If the economy starts below $n_{L}{ }^{*}$, it stays there, on (VV). Slightly above this level, it converges to $n_{H}{ }^{*}$. Finally, in Figure 3c, (NN) intersects (VV) twice, the lower intersection being where (VV) is upward sloping. In this case, even if $n_{0}$ is just below $n_{L}{ }^{*}$, expectations that are optimistic enough may generate dynamics that take the

\footnotetext{
${ }^{20}$ This can be generalized to non-CES forms, as is made clear in Ciccone and Matsuyama’s Proposition 2.
} 
economy to the steady state with $n_{H}{ }^{*}$ intermediate goods firms. It is clear that transaction costs have two potential impacts, in this case. First, they can reduce $n_{0}$, and thereby increase the likelihood that the economy stays in a low-level equilibrium. Second, by shifting the (NN) and (VV) curves, they can reduce the likelihood that any given $n_{0}$ is high enough to generate development, and, even if development takes place, they can reduce the long run equilibrium level of development. Thus, for example, lowering transaction costs might shift the economy from case 3a to case 3b, and 'get it going' out of an initial stagnant state.

To summarize the entire modeling exercise, we have proceeded by examining three levels of impact of transaction costs. First, there are the standard direct resource costs, which are larger than just the deadweight loss triangles. These resource costs are well understood and widely acknowledged. Second, there are additional losses of consumer surplus through reductions in the number of varieties produced. These costs were highlighted by Romer (1994), with an emphasis on tariffs, but also with a clear statement that the analysis applies to general transaction costs. The Romer analysis is still static, but points the way toward incorporation in a dynamic model. We have done this here by extending a model of Ciccone and Matsuyama (1996). The third impact of transaction costs is in possibly arresting the process of development, and/or reducing its long-run level. We relate this abstract discussion to case studies of IT use for transaction cost reduction in the next section. 

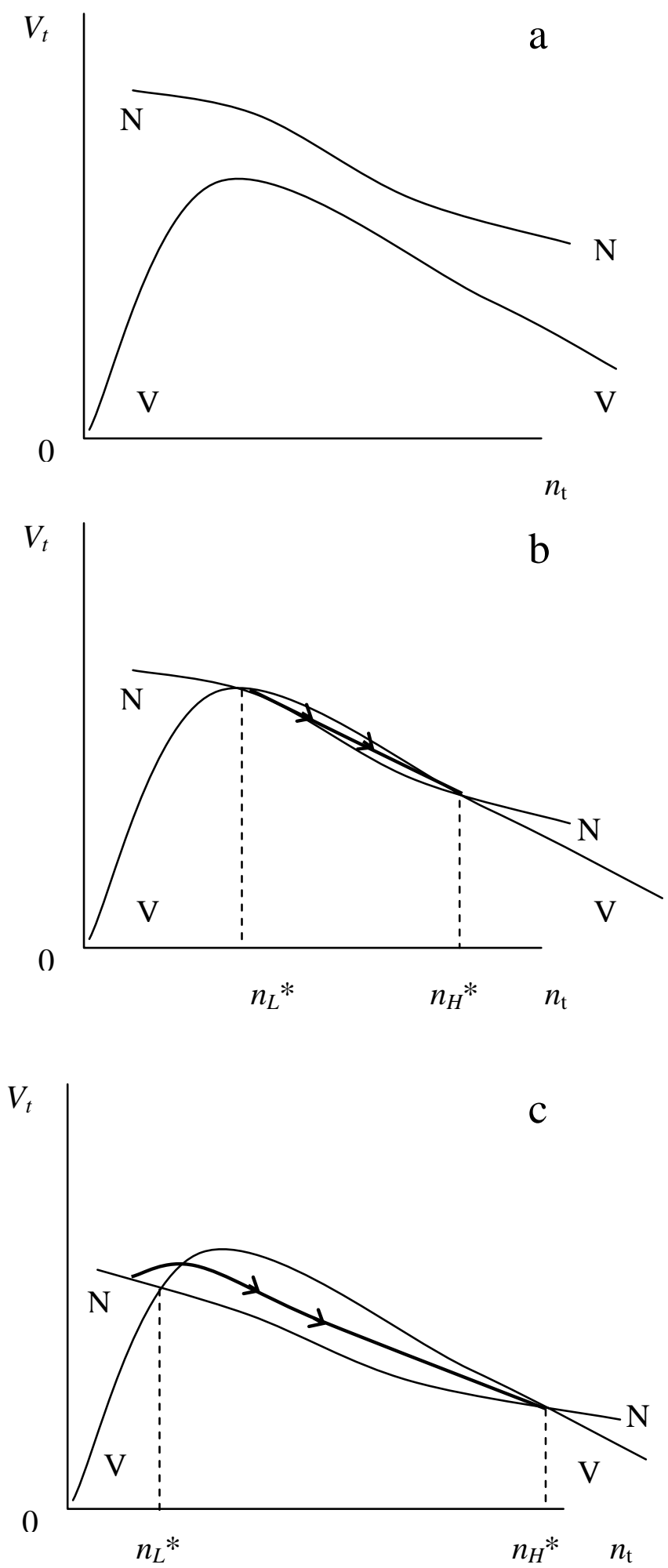

Figure 3 


\section{Rural Information Technology Use in India}

In this section, we use case studies from India to illustrate the potential impact of IT on rural development, particularly through the reduction of transaction costs. We can relate the discussion to the model sketched in the previous section by interpreting the intermediate goods in the model either as the outputs of rural farm households, or as their inputs - in the latter case, we think of the homogeneous final good as 'food,' or whatever crop is being grown. Either interpretation is possible, because it appears that both the range of inputs used by farmers in developing countries such as India, and the range of outputs that they produce, are constrained by high transaction costs. Our goal is to provide concrete illustrations of transaction costs reductions and their effects. ${ }^{21}$ In practice, their full impact remains to be seen, both in terms of static efficiency gains and of long run growth. In that respect, the link between the case studies and the modeling is tentative: nevertheless, this paper represents a significant first attempt to provide conceptual underpinnings for the understanding the development impacts of rural IT use in developing countries. Our discussion of several rural-IT initiatives in India is based on field visits conducted over a two-and-a-half year period, from December 2001 to July 2004, as well as discussions with various members of each organization. ${ }^{22}$

\section{Drishtee}

Drishtee.com had its origins in Gyandoot, a government project in Dhar district of Madhya Pradesh, in central India. Gyandoot provided an intranet for 33 village information kiosks, offering a range of mainly e-governance-related services. The most prominent of these was land record certificates, which are needed by landowners for transactions such as sale or leasing of land. While Gyandoot was a specific local initiative, involving heavy support from the local administration, Drishtee has attempted to take that model and rapidly replicate it across the country. Currently, Drishtee has approximately 100 rural Internet kiosks in several states, run by franchisees according to a revenue sharing arrangement. In Drishtee's case, a kiosk has, at least initially, just one computer. The set-up cost is in the range of Rs. 50,000 (approximately US \$1,000). A Drishtee kiosk is designed to serve about 10,000 people, and their target is to support 50,000 kiosks.

With the origins in Gyandoot playing a role, simple e-governance, such as making government forms available and allowing a variety of complaints to be relayed to the district level government, has typically been the lead service in setting up operations in a new district. In this context, informal partnerships with district level government officials

\footnotetext{
${ }^{21}$ We will not discuss issues of implementation and commercial feasibility. Those aspects are outlined in Singh (2004), on which this section does draw heavily. However, it is worth emphasizing here that falling costs of hardware, development of local software applications, and significant organizational innovations have all made rural IT provision at least close to economically sustainable on a large scale. In this interpretation of the model of Section 3, the provision of IT-based services to farmers represents new varieties of intermediate producer services, or lower transaction costs for existing services. In this case, a single firm may provide several varieties of services.

${ }^{22}$ It is important to reemphasize that the following is a subjective assessment, and does not reflect the views of any of the individuals or the organizations they represent.
} 
(both state and local government employees) have been very significant. For example, in Sirsa and Jaipur districts, Drishtee has been able to act as a significant intermediary for information exchange between the district government and constituents. It obviously remains limited in its ability to improve the internal functioning of government. Expanding the range of services has meant tying up with content partners, particularly organizations such as Agriwatch, which provides a substantial quantity and range of agricultural information to farmers, including global market prices, crop research, weather information, and web store fronts for inputs. Agriwatch is essentially developing into a large-scale Internet portal for farmers, and Drishtee's role can be seen as providing last-mile access to this rich information, through its kiosks. It is difficult to quantify the benefits of this service, but its popularity with farmers suggests that it is valuable. Related examples from the cases of ITC and n-Logue will provide a more definite assessment of these benefits.

Drishtee's pricing scheme for e-governance services follows a set model. The full cost of a transaction such as obtaining, filling out and submitting a government form is estimated, including imputing the value of time spent in travel. The kiosk owner's fee for this is then set at about 10 percent of the estimated transaction cost, also taking into account possible willingness-to-pay considerations in choosing "pricing points" such as Rs. 5, 10 or 20. Assuming that these fees can cover the full cost of the kiosk owner and Drishtee (which depends largely on generating sufficient volume) the saving in transaction costs is substantial. The savings in such cases are generated by reductions in travel and time costs. There may also be benefits in terms of improving the effectiveness of transactions (e.g., if a complaint through this channel s more likely to be addressed), but these are harder to quantify.

In the case of other services, such as matching buyers and sellers, or providing horoscopes or matrimonial advertising, additional services require partners who can provide software, maintenance, content or other components of the complete service. Education has played a limited role in Drishtee's offerings, though kiosk owners have often used the presence of a computer and peripherals to offer computer training, as well as other offline services such as printing and games. The benefits in these examples are reductions in transaction costs for existing transactions, improved quality of successful matches, and potentially most significant, completion of investment and consumption activities (e.g., training, entertainment, and long-distance communications) that would otherwise not take place because of high transaction costs.

\begin{abstract}
Aksh
Aksh is essentially a fiber optic cable company, with its core competence in laying and maintaining cable. Its revenue model is driven by the content and data that can be delivered over this cable. Therefore it has an interest in increasing such content delivery. While urban areas in India have seen substantial penetration of cable TV, through a model of largely unregulated local operators, the rural market remains largely unserved. $^{23}$ The bottleneck has been the lack of last mile infrastructure, since there are a

\footnotetext{
${ }^{23}$ Under pressure from content providers, the government, through the Telecoms Regulatory Authority of India, is attempting to regulate urban cable TV markets more stringently.
} 
significant percentage of rural households (especially in richer districts) that can afford cable TV. Aksh, along with other companies such as Reliance, has received licenses for laying a new fiber optic network in rural areas. In the case in point, Aksh rapidly laid a large fiber optic network in rural Jaipur district (excluding the city itself). It initially partnered with Drishtee for the development and maintenance of kiosks that would act as distribution points for cable TV access, as well as Internet kiosks. The Drishtee franchise model, interface and services were adopted, but with the brand name of "Gramdoot." Now Aksh serves as the main service provider, with Drishtee reduced to the role of providing software and related services. ${ }^{24}$

The history of Aksh's initiative means that the range of services provided in their kiosks, the revenue model, and pricing structures currently follow the Drishtee model. Hence the earlier discussion of benefits transfers over to this case. The importance of cable TV revenues, however, suggests that these kiosks may emphasize a range of entertainment services more than utility services such as agriculture-related information or e-governance. It is conceivable, however, that kiosk operators will be able to span the entire range of services. The bandwidth available will certainly support a full range of offerings, and the issues will be managerial attention and the perceptions of rural users. One important implication of greater bandwidth is that video interactions are possible, and Drishtee and Aksh have been able to test several communication services based on this. The power of video over text is in increasing the richness of information exchange, as well as greatly increasing the attractiveness and acceptance of all the services offered by the kiosks.

\section{N-Logue}

While Drishtee is mostly active in northern and eastern India, n-Logue has its origin in the south of India, and its chief presence there and in western India. It is a forprofit corporation, with majority ownership residing with a nonprofit organization. The main impetus for n-Logue came from the IIT Chennai research group headed by an IIT professor, Ashok Jhunjhunwala. This group has been responsible for a stream of hardware and software innovations that enable rural IT-based service delivery, through connectivity and applications. The core innovation at the heart of n-Logue's operations is a Wireless-in-Local-Loop (WLL) technology that provides joint wireless Internet and voice connectivity. The kiosk-level hardware is relatively inexpensive, and adds only marginally to the overall cost of a kiosk. However, the construction of WLL towers and maintenance of the WLL hub is relatively costly, and this fixed cost requires a substantial density of kiosks within a particular radius of the tower. The n-Logue model is designed to achieve this density, with kiosks generating returns from fairly small user populations. In fact, n-Logue claims to be able to make kiosks commercially viable serving populations as small as 1500 . With a goal of 500,000 kiosks, it aims to eventually serve 750 million people, or virtually all of India's rural and small town population. N-Logue is the currently the second largest organization in this field, supporting over 1000 rural-IT kiosks.

\footnotetext{
${ }^{24}$ There are several reasons for this shift in the business relationship, including Aksh's far greater resources and capabilities, the different needs of the cable TV business, and Aksh's incentive to control and brand the effort to score points for corporate social responsibility.
} 
$\mathrm{N}$-Logue has progressed well beyond being simply a connectivity provider, to delivering a range of services - these can be adapted to different connectivity technologies. The WLL technology overcomes lack of dial-up connectivity, and provides an extra revenue stream for kiosk operators, through voice calls. Furthermore, it has greater bandwidth than traditional fixed line dial-up, which allows a wide range of applications to be delivered. In particular, the IIT Chennai group has been able to develop video applications that are sufficiently compressed to work within the constraints of the WLL. The close links with the IIT Chennai group have given n-Logue access to a range of software innovations for delivery and implementation of various applications in the fields of education, health and agriculture. For example, web cams have been used for remote diagnostics for diseases of people, animals and plants. Distance learning programs have also been developed. A considerable amount of local language software has been created quite rapidly and effectively to support these applications. In many of these cases, the transactions (eye exam, animal check-up, learning basic computer skills, etc.) would not have taken place for many of the households involved, because the costs of obtaining these services by more traditional means would have been too high. In most of these cases, the services provided can be viewed as new, productivity-enhancing inputs into the production of rural households. This availability of new producer services represents the connection with the formal model developed in Section 3.

$\mathrm{N}$-Logue has also been able to build partnerships for the delivery of additional services. ICICI Bank, headquartered in Mumbai in western India, is piloting various financial services products, including insurance and banking, in kiosks in Madurai and Thirupattur districts in the state of Tamil Nadu. The use of IT kiosks for delivering rural financial services is perhaps potentially the most significant example of reducing transaction costs. $^{25}$ Despite some headway made by nationalized banks and credit cooperatives in serving rural markets, it is not difficult to come across cases of farmers paying monthly interest rates that equal, in percentage terms, what corporate or urban household borrowers pay per annum. Bank credit is often not available to small farmers, precisely because the transaction costs are too high for rural branches of nationalized banks. Microcredit has filled some of the gap, but it remains relatively small in total, reflecting its own high transaction costs when scaling up is attempted. ${ }^{26}$ Rural IT kiosks may provide low cost delivery points for rural financial services that occupy an empty space between microcredit at the low end, and traditional bank branches and cooperatives at the high end.

One of the barriers to rural credit provision at reasonable interest rates is the continued existence of interlinking. ${ }^{27}$ Surprisingly, perhaps, this is not just a characteristic

\footnotetext{
${ }^{25}$ In fact, ICICI bank is working with several rural IT initiatives in other areas of India, in addition to nLogue and Drishtee. For example, see ICICI Bank (2004).

${ }^{26}$ For example, Nancy Barry, President Women's World Banking (WWB), USA, states that "You need to recognize the transaction costs are high in microfinance... focus on cutting transaction costs in microfinance through new technology and channels” Barry (2004).

${ }^{27}$ On this point, see the perceptive comments in Bardhan (1989), where the role of transaction costs in interlinking is emphasized. Ray and Sengupta (1989) provide a formal analysis of different types of
} 
of 'backward' states such as Bihar. For example, in the relatively high-income state of Punjab, cotton farmers still rely on commission agents who provide input credit, guaranteed purchases of output, and some implicit insurance. Reducing transaction costs of alternative sources of credit may not be enough to overcome high switching costs in such cases, unless transaction costs in input and output markets are also reduced. IT kiosks have this precise capability. For example, in Nellikuppam district of Tamil Nadu, n-Logue has partnered with EID-Parry to improve sugar farmers' access to information, and reduce their transactions costs in dealing with Parry's large sugar factory in the district, through improved tracking and settlements of payments. ${ }^{28}$ Combining this approach to marketing farmers' output with new credit channels may provide an alternative to traditional interlinking of input credit and output purchases. Parry also plans to use those kiosks that are under its own brand (several dozen in total) to offer processed foods to farmers. Thus, it is possible that IT kiosks can reduce transaction costs (and expand variety) in three different markets: farm inputs, farm outputs, and manufactured products (of which processed foods are one example).

\section{ITC}

ITC stands out among the firms considered here, since it is a large Indian corporation serving global markets. Its kiosks are called e-choupals, and they have several differentiating features. The key distinguishing factor is that the e-choupals are totally designed to support ITC's agricultural products supply chain. This gives them a focus that is not present even in EID-Parry's kiosks in Nellikuppam. In addition, the echoupals are totally owned and set up by ITC, with the operators not having any investment or risk of their own. Furthermore, e-choupal operators are, because of the focus, always relatively well-off farmers, with social standing in the village, and therefore they are always male. All these features make the e-choupals different from the previous three initiatives. There are four kinds of e-choupals, tailored very specifically for four different products: shrimp, coffee, wheat and soybeans. The first two of these involve large commercial farmers, and the focus is on creating Internet access to global market information to guide production and supply decisions. There are a few dozen of these e-choupals. In the case of wheat and soybeans, there are many small farmers, and over 3,000 e-choupals have been set up, in several states of India.

The description in this paper is based on soy-choupals in Madhya Pradesh state. Wheat-choupals are somewhat similar, though the final market and products are somewhat different. Soybeans are pressed to extract oil, which is sold domestically, while the remainder is exported as animal feed. Thus they are a cash crop, without the regulated market conditions or subsistence consumption associated with a food grain such as wheat. Soy-choupals are used as registry points for procurement of soybeans. Actual procurement is done at factories and warehouse hubs, but the initial logging in is done through the e-choupal, which provides price information and therefore price certainty. In fact, the e-choupal price acts as a floor price for procurement - the factory or warehouse

interlinking, and further references. Bardhan and Rudra (1978) performed the seminal empirical work on interlinking. For recent empirical work on interlinking in Punjab, see Gill (2003).

${ }^{28}$ In this case, the factory chimney has also served as a base for the tower, and the control hub is housed in the factory, substantially reducing fixed costs. 
price can be higher. E-choupals also provide access to local market (mandi) prices and global market price information on soybeans and derivative products, to allow farmers to compare prices. They give access to operational information, developed by ITC experts, pertaining to cropping, seeds, fertilizer, and so on.

E-choupals are set up by ITC, with solar power backup and VSAT connectivity. The equipment cost for the e-choupal is borne by ITC, with the selected farmer providing the location. E-choupal farmers take an oath to serve the village, and they are trained by ITC. While there is an important element of social pressure and pride of work, the operators also receive commissions on soybean shipments booked through the echoupals. This provides substantial revenue to the e-choupal operator. The narrow (at least initial) focus of the e-choupals and the substantial commitment of financial and human resources by ITC has made rapid expansion possible, as well as quick acceptance by farmers. The longer-term goal is to use e-choupals and warehouse hubs as sales points for soybean oil, tractor rentals, and eventually a range of ITC-produced consumer goods.

The initial benefits of the ITC effort include a substantial reduction in transaction costs, from approximately 8 percent of a transaction, down to about 2 percent. It is estimated that these gains are shared roughly equally between ITC and individual farmers. Some of this gain may be at the expense of traditional intermediaries, who operate in mandis, but much of it comes from genuine efficiency gains, including clearer quality guidelines and measurement, greater timeliness and reduced wait times, quicker payments, and reduced uncertainties. To some extent, traditional intermediaries are coopted in the new process, by being hired to perform tasks such as handling payments at ITC's receiving points. Note that traditional intermediaries often have monopoly power, which drives a wedge between buyers and sellers that exceeds the value of the services provided. In that sense, IT reduces transaction costs by also providing competition in intermediation - this is related to the earlier discussion of credit markets. ${ }^{29}$ Finally, while a 6 percent or lower saving may seem quite small, it is worth noting that this is a percentage of gross revenue. Hence, it is likely to be a much larger fraction of value added. For example, if a farmer's net profit rate on a transaction is 25 percent of revenue before transaction costs, a gain of 3 percent on the transaction through reduced transaction costs represents a 12 percent increase in profit.

Clearly the use of information technology is just a part of ITC's overhaul of its supply chain, but speedy delivery of complex information pertaining to market conditions makes IT essential. It might be asked what acts as a check on ITC's market power in this process. The traditional mandi (grain market) system, with its accompanying government regulation and oversight, acts as continuing competition. More significantly, ITC's concern with its reputation acts as a disciplining device. Finally, the long-term goal of selling back to farmers as customers also gives ITC an incentive to cultivate relationships

\footnotetext{
${ }^{29}$ Of course, IT is not the only possible source of transaction cost reductions, and in some cases, it may be of no value. In the ITC case, the value of the information and implicit insurance provided is all dependent on the existence of physical market access by road, and ITC's procurement infrastructure. In other cases, however, such as education, crop information, and preliminary medical diagnosis, IT may be valuable even in the absence of a transportation infrastructure. I am grateful to T. N. Srinivasan for clarifying this point.
} 
with individual farmers. In fact, farmers view ITC as treating them with much greater respect and dignity than is the case in traditional mandi interactions.

It is possible that the ITC model will not broaden significantly beyond the twoway flow of agricultural produce from farmers to ITC, and processed foods, consumer goods and inputs from ITC to farmers, without extending to e-governance, entertainment, health or education-related services. Instead, other firms may provide these services in similar locations to ITC e-choupals. In any case, all the different IT implementation models illustrate substantial savings of transaction costs, and indicate that the result may be new transactions and new products being offered.

The four organizations discussed above are just some of the increasing number of rural IT providers in India. In addition to these private initiatives, there are also various government efforts. There are also more focused examples of IT use for reducing transaction costs, such as the case of milk cooperatives, where measurement, quality testing, and payment are all facilitated by IT use, reducing transaction costs substantially. While in most cases the gains are difficult to measure, whatever quantitative estimates there are suggest that transaction costs can be reduced substantially through the use of IT. While the net resource saving must also take account of the fixed costs of setting up and maintaining the IT infrastructure, the performance of rural IT kiosks run as franchises indicates that they are often able to cover all running costs as well as the cost of capital. There is also accumulating evidence of new goods and services being provided to rural households through these IT kiosks. While there is no direct confirmation of the theoretical model of Section 3, one can argue that the model is indicative of the process of development that might be stimulated by the deep penetration of IT in rural areas in developing countries.

\section{Information Technology and Development: Closing Thoughts}

While the empirical evidence we have provided for the possible positive impacts of IT on development came from rural India, one can argue that similar benefits might be attainable throughout the economy. To the extent that India, or any developing country, is a high transaction cost economy, anything that reduces these transaction costs (whether through policy or technology) anywhere in the economy can play a role in stimulating development. In particular, if IT can reduce transaction costs for the modern manufacturing or services sectors in India, it can have a positive impact there as well. India's use of IT for providing all kinds of outsourcing services to global markets is one possible example, since IT's key role in that case is reducing long-distance communication costs. In this paper, we have focused on rural IT use because it is perhaps the most striking case, and because the majority of the population of developing countries lives in rural areas.

Furthermore, in working out the positive impacts of IT on economic growth, we have focused in this paper on the channel of reduced transaction costs. However, IT can have several other channels of impact, and we close with a brief discussion of these. For 
example, if IT increases the efficiency of education delivery to the broader population, this investment in people (human capital acquisition) is also likely to lead to higher growth. ${ }^{30}$ IT may also have positive impacts through impacts on the innovation process. For example, IT can make innovation easier by allowing simulation and low-cost testing of new designs or searching through possible chemical compounds for beneficial drugs. Also, IT may speed the diffusion of innovations through better communications, which may stimulate further innovation.

A growth model that captures well the special role of IT in economic growth, as an enabler of efficient communication and storage of information, is an extension of the recombinant growth model of Weitzman (1998). The central idea of this approach is that new ideas are formed through combinations of old ideas. A key property of this formulation is that the increase in the number of ideas is faster than geometric growth (Weitzman, 1998, Lemma, p. 338). The rate at which potential ideas are converted into new ones depends on the level of resources spent per potential 'hybrid seed idea', i.e., R\&D. If one modifies Weitzman's model to allow the stock of IT knowledge to independently affect this success rate, IT gives the growth process an extra 'kick', beyond that which comes from recombinant growth in general. ${ }^{31}$

Some final impacts of IT on development, broadly defined, emerge from the India case studies. A factor that seemed to emerge in all cases was the greater average success of women kiosk operators, possibly reflecting the fact that there is greater untapped potential for rural women, given their otherwise more restricted employment opportunities. Certainly, rural IT kiosks provide an important new employment avenue for women who are constrained by social norms from commuting or migrating for work. For both women and men, the kiosk operations were often viewed as boosting selfesteem, capabilities and awareness of possibilities. This extended beyond the operators themselves, to the rural clientele. Children, in particular, were quick to see and seize possibilities associated with IT use, including learning new skills, communicating more widely, and improving their entertainment options. These observations can also be related to the growth model considered in Section 3: in case 3c, the dynamics of the economy depended on expectations, and anything that makes these expectations more positive may have long-run impacts. ${ }^{32}$ In cases where e-governance services were introduced, there was a heightened awareness of civic roles and the responsibilities of government at the local level. While one cannot claim that IT automatically provides all these benefits, it is certainly the case, that by providing large scale and widespread access to new information, and to new transaction opportunities in an affordable manner, IT appears to be poised to play a broad role in economic development in countries such as India.

\footnotetext{
${ }^{30}$ For example, Lucas (1988) is an early growth model emphasizing human capital. Barro (2001) is one of many empirical studies exploring the relationship between human capital and growth.

${ }^{31}$ See Singh (2003) for details of the model and further discussion.

32 This argument has been made informally, in the context of India's success in software exports (Kapur, 2002). Rural IT penetration potentially extends these optimistic expectations to a much broader population.
} 


\section{References}

Bardhan, Pranab K. (1989), A Note on Interlinked Rural Economic Arrangements, in The Economic Theory of Agrarian Institutions, ed. Pranab K. Bardhan, Oxford: Oxford University Press, pp. 237-242.

Bardhan, Pranab K. and Ashok Rudra (1978), Interlinkage of Land, Labour and Credit Relations: An Analysis of Village Survey Data in East India, Economic and Political Weekly, Vol. 13, Annual Number, February.

Barro, Robert J. (2001), Human Capital and Growth, American Economic Review, May, 91(2), pp. 12-17.

Bhatnagar, Subhash and Robert Schware (2000), Information and Communication Technology in Development: Cases from India, New Delhi: Sage Publications.

Bussolo, Maurizio (2001), How Many Forms Do I Have to Fill in to Export My Coffee? The Role of Transaction Costs in Explaining Economic Performance in Latin America, Paper prepared for conference on Impacts of Trade Liberalisation Agreements on Latin America and the Caribbean, Inter-American Development Bank, Washington, D.C., accessed on September 10, 2004 at

www.cepii.fr/anglaisgraph/communications/pdf/2001/washington/bussolo.pdf.

Barry, Nancy (2004), Presentation at Plenary Session - Policies, Regulation, Governance and Systems that Promote Sustainable Financial Institutions for Poor and the Poorest. Microcredit Summit E-News, 2 (3), August, at www.microcreditsummit.org/enews/200408_plenary.html, accessed October 28, 2004.

Bussolo, Maurizio and John Whalley (2002), Globalization in Developing Countries: The Role of Transaction Costs in Explaining Economic Performance in India, Globalisation and Poverty Programme, Department For International Development, UK, September.

Ciccone, Antonio and Kiminori Matsuyama (1996), Start-up Costs and Pecuniary Externalities as Barriers to Economic Development, Journal of Development Economics, 49 (1), pp. 33-59.

Coase, Ronald (1937), The Nature of the Firm, Economica, 4, pp. 386-405.

de Soto, Hernando (1989), The Other Path, Harper and Row, New York.

Foley, Duncan K., (1970), Economic Equilibrium with Costly Marketing. Journal of Economic Theory, 2 (3), pp. 276-291.

Funke, Michael and Ralf Ruhwedel (2003), Trade, Product Variety and Welfare: A Quantitative Assessment for the Transition Economies in Central and Eastern Europe, Bank of Finland Institute for Economies in Transition Working Paper No. 17, December. 
Gill, Anita (2003), Interlinked Agrarian Credit Markets in a Developing Economy: A Case Study of Indian Punjab, paper presented in the International Conference on Globalization and Development Organized by The Development Studies Association, U.K., at University Of Strathclyde, Glasgow 10-12 September, at www.devstud.org.uk/publications/papers/conf03/dsaconf03gill.pdf (accessed October 28, 2004)

Grossman, Gene M. and Elhanan Helpman, 1991, Innovation and Growth in the Global Economy, MIT Press, Cambridge, MA.

Hahn, Frank H., (1971), Equilibrium with Transaction Costs. Econometrica, 39 (3), pp. 417-439.

Hummels, David and Peter J. Klenow (2002), The Variety and Quality of a Nation's Trade, Working Paper 8712, National Bureau of Economic Research, January.

ICICI Bank (2004), ICICI Bank Launches Kisan Loan Card and Inaugurates Innovative Low Cost ATMs in Rural India, Press Release, September 1, at www.icicibank.com/pfsuser/aboutus/investorelations/pressrelease/icicibank_pressrealeas e/Kisan_Loan_Card.pdf (accessed October 28, 2004).

Kapur, Devesh (2002), The Causes and Consequences of India’s IT Boom, India Review, 1 (1), pp. 91-110.

Kaushik P. D., and Nirvikar Singh (2004), Information Technology and Broad-Based Development: Preliminary Lessons from North India, World Development, 32 (4), pp. 591-607.

Kehoe, Timothy and Kim J. Ruhl (2003), How Important Is the New Goods Margin in International Trade?, Federal Reserve Bank of Minneapolis Research Department Staff Report 324, October.

Lucas, Robert E. (1988), On the Mechanics of Economic Development, Journal of Monetary Economics, 22, pp. 3-42

Obstfeld, Maurice and Kenneth Rogoff (2000), The Six Major Puzzles in International Finance: Is There a Common Cause?, NBER Macroeconomics Annual, 15.

Panagariya, Arvind (2004), India’s Trade Reform: Progress, Impact and Future Strategy, Columbia University Working Paper, accessed on September 10, 2004 at econwpa.wustl.edu:8089/eps/it/papers/0403/0403004.pdf.

Ray, Debraj and Kunal Sengupta (1989), Interlinkages and the Pattern of Competition, in The Economic Theory of Agrarian Institutions, ed. Pranab K. Bardhan, Oxford: Oxford University Press, pp. 243-263.

Romer, Paul (1994), New Goods, Old Theory, and the Welfare Costs of Trade Restrictions, Journal of Development Economics, 43 (1), pp. 5-38. 
Singh, Nirvikar (2002), Information Technology as an Engine of Broad-Based Growth in India, in The Information Economy in India, ed. Parthasarathi Banerjee and Frank-Jürgen Richter, London: Palgrave/Macmillan, pp. 24-57.

Singh, Nirvikar (2003), India's Information Technology Sector: What Contribution To Broader Economic Development? OECD Development Centre Working Paper 207, www.oecd.org/dataoecd/59/12/2503442.pdf.

Singh, Nirvikar (2004), Information Technology and Rural Development in India, in Integrating the Rural Poor into Markets, in Bibek Debroy and Amir Ullah Khan, eds., New Delhi: Academic Foundation, pp. 221-246.

Weitzman, Martin (1998), Recombinant Growth, Quarterly Journal of Economics, 113 (2), pp. 331-360.

Williamson, Oliver E. (1975), Markets and Hierarchies: Analysis and Antitrust Implications, New York: The Free Press.

Williamson, Oliver E. (1981), The Economics of Organization: The Transaction Cost Approach, American Journal of Sociology, 87 (3), pp. 548-577. 